\title{
Whole of Systems Trial of Prevention Strategies for Childhood Obesity: WHO STOPS Childhood Obesity
}

\author{
Steven Allender ${ }^{1, *}$, Lynne Millar ${ }^{1}$, Peter Hovmand ${ }^{2}$, Colin Bell ${ }^{1,3}$, Marj Moodie ${ }^{1,4}$, \\ Rob Carter ${ }^{4}$, Boyd Swinburn ${ }^{1,5}$, Claudia Strugnell ${ }^{1}$, Janette Lowe ${ }^{6}$, Kayla de la Haye ${ }^{7}$, \\ Liliana Orellana ${ }^{8}$ and Sue Morgan ${ }^{9}$ \\ 1 Global Obesity Centre (GLOBE), World Health Organization Collaborating Centre for Obesity Prevention, \\ Faculty of Health, Deakin University, Melbourne 3125, Australia; lynne.millar@deakin.edu.au (L.M.); \\ colin.bell@deakin.edu.au (C.B.); marj.moodie@deakin.edu.au (M.M.); boyd.swinburn@auckland.ac.nz (B.S.); \\ claudia.strugnell@deakin.edu.au (C.S.) \\ 2 Brown School's Social System Design Lab, Washington University, St Louis, MO 63130, USA; \\ phovmand@wustl.edu \\ 3 School of Medicine, Faculty of Health, Deakin University, Melbourne 3125, Australia \\ 4 Deakin Health Economics, Centre for Population Health Research, Faculty of Health, Deakin University, \\ Melbourne 3125, Australia; rob.carter@deakin.edu.au \\ 5 Population Nutrition and Global Health, University of Auckland, Auckland, NZ 1142, USA \\ 6 Southern Grampians and Glenelg Primary Care Partnership, Hamilton, NZ 3300, USA; \\ Janette.Lowe@wdhs.net \\ 7 Department of Preventive Medicine, University of Southern California, Los Angeles, CA 90033, USA; \\ delahaye@usc.edu \\ 8 Biostatistics Unit, Faculty of Health, Deakin University, Melbourne 3125, Australia; 1.orellana@deakin.edu.au \\ 9 Victorian Department of Health and Human Services, Geelong 3220, Australia; sue.morgan@dhhs.vic.gov.au \\ * Correspondence: steven.allender@deakin.edu.au; Tel.: +61-3-5227-8395
}

Academic Editor: Paul B. Tchounwou

Received: 18 October 2016; Accepted: 10 November 2016; Published: 16 November 2016

Abstract: Background: Community-based initiatives show promise for preventing childhood obesity. They are characterized by community leaders and members working together to address complex local drivers of energy balance. Objectives: To present a protocol for a stepped wedge cluster randomized trial in ten communities in the Great South Coast Region of Victoria, Australia to test whether it is possible to: (1) strengthen community action for childhood obesity prevention, and (2) measure the impact of increased action on risk factors for childhood obesity. Methods: The WHO STOPS intervention involves a facilitated community engagement process that: creates an agreed systems map of childhood obesity causes for a community; identifies intervention opportunities through leveraging the dynamic aspects of the system; and, converts these understandings into community-built, systems-oriented action plans. Ten communities will be randomized (1:1) to intervention or control in year one and all communities will be included by year three. The primary outcome is childhood obesity prevalence among grade two (ages 7-8 y), grade four (9-10 y) and grade six (11-12 y) students measured using our established community-led monitoring system (69\% school and 93\% student participation rate in government and independent schools). An additional group of 13 external communities from other regions of Victoria with no specific interventions will provide an external comparison. These communities will also allow us to assess diffusion of the intervention to control communities during the first three years of the trial. Conclusion: This trial will test effectiveness, over a five-year period, of community-owned, -supported and -led strategies designed to address complex and dynamic causes of childhood obesity.

Keywords: community prevention; childhood obesity; systems thinking; cluster randomized controlled trial; social network analysis; economic analysis; anthropometry; obesogenic behaviours 


\section{Introduction}

Obesity is a major determinant of Type 2 diabetes, coronary heart disease, and cancer. In Australia, obesity costs the health system more than $\$ 21$ billion annually [1] and more than one-quarter (28\%) of Australian children are overweight or obese [2]. The size and scope of the burden, together with overweight youth having a 70\% chance of becoming obese adults [3], make the case for prevention compelling. Children are a critical focus for prevention because they are so susceptible to the environment and because treatment is difficult. Childhood obesity has been recognized as a priority in the WHO's Global 2013-2020 Action Plan for the Prevention and Control of Non Communicable Disease [4] and recommendations have been provided to countries on ending childhood obesity [5].

Recent Cochrane meta-analysis of childhood obesity interventions showed an overall benefit for community-based interventions among primary school-aged children [6]. The 55 studies reviewed evaluated mainly small, discrete interventions delivered over the short term and not "scaled up" to population levels. Several successful community-based studies [7-9] showed that improving broader system determinants (e.g., community capacity), strongly predicts the degree of reduction in childhood obesity [10]. The 2015 Lancet Obesity Series [11] identified the challenge for community-based childhood obesity prevention initiatives as the creation of sustained, large-scale interventions that work at multiple levels [12].

Several attempts have been made or are underway to work at population scale in Australia (e.g., Healthy Together Victoria), New Zealand [13] and England [14]. These population-level interventions begin by fostering a shared understanding of the systemic determinants of non-communicable disease and asking how existing systems can be strengthened or new systems created to better promote health and prevent disease [15]. One of the clear messages from previously successful trials is that building community capacity to apply systems thinking is critical [10]. Systems thinking is characterized by attempts to identify the most important cause and effect relationships within a specific system boundary that create feedback and so amplify or stabilise change across a system. System dynamics, an approach to systems thinking, explicitly seeks to create informal maps and formal simulation models of this dynamic complexity [16]. While many more traditional interventions have focused on linear cause-and-effect relationships, systems interventions focus on non-linear relationships (e.g., tipping points), feedback where a "causal" variable might in turn be impacted by an "outcome variable", and complexity in the multilevel factors involved, as well as multiplex relationships among these factors.

New methods are required that facilitate communities' and researchers' ability to measure the components and processes of relevant systems (i.e., systems that impact childhood obesity in their community), to map and understand these systems, and to use systems data and models in real time to implement change and make ongoing improvements at multiple levels. Similarly, new methods are required to integrate economic analysis into systems approaches so that cost-effectiveness can be measured.

In this paper, we present the protocol for the Whole of Systems Trial of Prevention Strategies for childhood obesity (WHO STOPS childhood obesity) trial. This trial has grown out of strong partnerships between researchers and community leaders in the Great South Coast Region of Victoria (GSCRV), Australia. Shared work in preparation for this study has included creation of: (1) a sustainable and high participatory obesity-monitoring system; and (2) whole of community systems measures and interventions.

\subsection{A Sustainable Monitoring System}

In 2015, a childhood obesity-monitoring system was established across six local government areas in South-Western Victoria [17]. We used locally sourced competitive funding to conduct training, manage data collection, conduct analysis and support an in-kind contribution from health services, local government and schools to conduct data collection. Anthropometric and behavioural data were 
collected from $90 \%$ of children in 48 of the 84 primary schools in the GSCRV. Partners have committed to provide in-kind support to collect these data again in 2017 and 2019.

\subsection{Whole of Community Systems Measures and Interventions}

The researchers and community leaders have developed and piloted a range of systems action tools and techniques to build community capacity and ownership of efforts to apply system thinking to community-wide childhood obesity prevention.

This paper sets out a protocol for the WHO STOPS Obesity project designed to bring all these lessons together and test the efficacy and cost-effectiveness of the approach for preventing obesity among primary school-aged children in South-Western Victoria, Australia.

The trial is registered by the Australian New Zealand Clinical Trials Registry (ACTRN12616000980437).

\section{Methods}

This is a cluster randomized stepped wedge trial (two steps) in ten communities. The unit of randomisation and intervention is the community (rather than individual children). Following baseline measurement of all eligible children in all ten communities (2015), five communities will be randomized to the intervention in year one (step one) and the remaining five will be entered into the intervention two years later (step two) (Table 1). Grades two, four and six children in all clusters will be measured in the baseline year (2015), year two (2017) and year four (2019). Data collection every second year reflects a more cost-effective measurement approach and a realistic timeframe to begin to see changes in weight status among intervention populations. Opportunities and funding for longer-term data collection (i.e., a five- and ten-year follow up) will be actively sought in due course.

Table 1. Study design for the WHO STOPS cluster randomized controlled trial.

\begin{tabular}{ccccccc}
\hline Community Type & $\boldsymbol{n}$ & Baseline & \multicolumn{2}{c}{ Step 1 } & \multicolumn{2}{c}{ Step 2 } \\
\hline Participant & 5 & $\# *(0)$ & $\#(0)$ & $\# *(0)$ & ${ }^{*} \mathbf{( 1 )}$ & $\#^{*}(\mathbf{2})$ \\
communities & 5 & $\# *(0)$ & $\# \mathbf{( 1 )}$ & $\# *(\mathbf{2})$ & ${ }^{*}(\mathbf{3})$ & $\# * \mathbf{( 4 )}$ \\
\hline External control & 13 & $*(0)$ & $(0)$ & $*(0)$ & $(0)$ & $*(0)$ \\
\hline Year & & 2015 & 2016 & 2017 & 2018 & 2019 \\
\hline
\end{tabular}

\# Data collection systems mapping; * Date collection individual outcomes; $(X)=$ Years in intervention group; Data in bold denotes intervention period.

\subsection{Study Population}

The units of observation are all primary school-aged children in grades two, four and six (aged approximately 6 to 12 years) $(n=5050)$ in ten communities of the GSCRV. Clusters, or "natural communities", are distinct, dispersed population centres agreed by partners based on existing government, health service, and education boundaries (see Figure 1). The ten enrolled clusters will be ranked in order of size, and one community from each quintile will be randomly allocated to intervention at step one. Blinding and allocation concealment is not possible in trials where whole communities are recruited into the design, implementation and evaluation.

This stepped wedge design $[18,19]$ is particularly suited to situations where: randomisation of individuals is not possible (i.e., population level trials); the intervention is expected to be of benefit and unlikely to do any harm (i.e., where previous small-scale interventions have been successful); and, where allocation of communities to a control-only arm would be problematic, unethical, or likely to result in communities refusing to participate $[20,21]$. The design provides strong analytic qualities, with intervention/control exposure and comparison available both within and across arms [22,23]. The trial described requires intensive support efforts across multiple communities and so it is not feasible to deliver it across all communities simultaneously. It is also designed iteratively so that subsequent communities benefit from lessons learned from the preceding communities. 


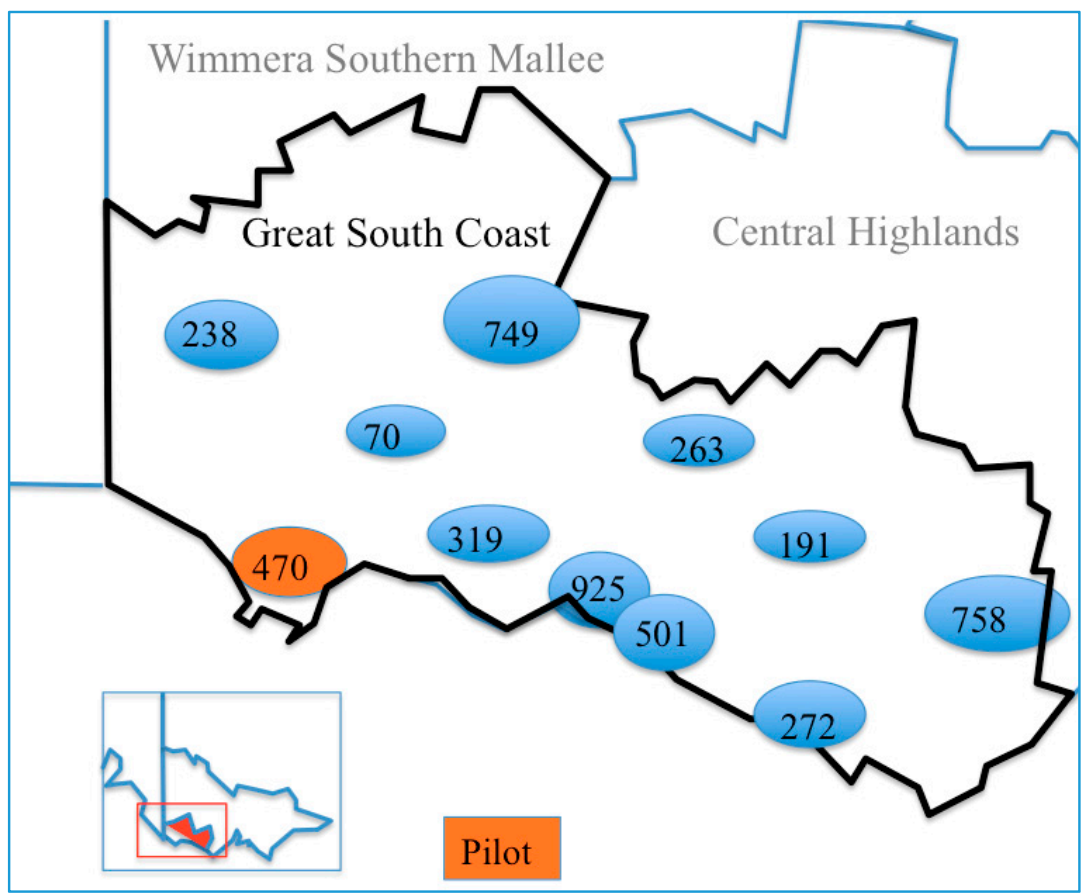

Figure 1. Estimated number of eligible children (grades two, four and six) in study region: $n$ presented in shaded bubbles.

\subsection{Intervention}

Intensive training and support within each intervention community will be oriented around strengthening WHO systems building blocks [24,25] (leadership, workforce development, resources, intelligence) and the New South Wales capacity-building framework [26] (partners and networks) in community settings. This includes mapping existing systems and using these maps to develop and implement whole of systems change with community members and implementation support to optimize interventions. Our pilot work [27] shows that community members were able to identify multiple systems that impact childhood obesity (examples range from improvements in individual health literacy, changes to school food and physical environments, banning of sugar-sweetened beverages within institutions, and local government regulation for better health) and design interventions that consider non-linearity, feedback and complexity.

The system intervention will be implemented by community members (parents and leaders from local government, education, clubs, health agencies, and businesses) with influence on environments in which children experience the key obesity risk factors. Partners will convene new and existing coalitions of community leaders who have the authority, capacity, and networks to lead systems change across the community. These leaders will form a steering group comprising members who are prepared to prioritize changing community systems to healthier food choices, physical activity and childhood obesity prevention across the intervention design process (Table 2). The process is typically conducted within a six-week period with six monthly reviews to capture systems change.

This systems-oriented intervention is similar to previous community capacity-building interventions [28] but builds on them in a number of critical ways. It adds: (1) a new way of thinking about embedding actions in systems; (2) an explicit picture of current community assets in relation to systems; (3) a process for enhancing community engagement in their own systems; (4) a dynamic logic model that adapts to change rather than a fixed linear model; (5) a planning tool for developing and prioritizing a broader set of community-wide actions; (6) a communications device to engage wider stakeholders; (7) a set of tools for community diagnostic and evaluative measurements; (8) an approach that is scalable and sustainable; (9) economic evaluation that utilizes conventional appraisal alongside 
newer approaches that capture interactions and dynamic changes through time; and, (10) empirical evaluation of the participating community partners' social networks, and roles that these social networks play in intervention diffusion and increasing community capacity.

Table 2. Intervention design activities.

\begin{tabular}{ll}
\hline Workshop & Content \\
\hline $\begin{array}{l}\text { 3 h Workshop 1 } \\
\text { Problem Identification }\end{array}$ & $\begin{array}{l}\text { Background, evidence, plan presentation; fill in community capacity index; } \\
\text { develop system logic model for "causes of childhood obesity in their } \\
\text { community" (outcomes evidence translation, baseline measurements, } \\
\text { base systems model). }\end{array}$ \\
\hline $\begin{array}{l}\text { 3 h Workshop 2 } \\
\text { Problem Refinement }\end{array}$ & $\begin{array}{l}\text { Further evidence presentation; fill in social network analysis questionnaires; } \\
\text { validation of system logic model on contextualised caused of childhood } \\
\text { obesity constructed from the previous workshop (outcomes-further baseline } \\
\text { data and knowledge translation and first validation of model). }\end{array}$ \\
\hline $\begin{array}{l}\text { Half-day Workshop } \\
\text { and Prioritisation }\end{array}$ & $\begin{array}{l}\text { Steering group recruits between 50 and 200 champions from across the } \\
\text { community who validate the systems logia model and identify priority } \\
\text { actions for each sub-system (e.g., water system, school system, food system) } \\
\text { related to them (outcomes; wider community validation of model and } \\
\text { action plans). }\end{array}$ \\
\hline $\begin{array}{l}\text { 2 h Workshop 2 } \\
\text { Solution Integration }\end{array}$ & $\begin{array}{l}\text { Review the consolidated priority actions (outcomes; translate to } \\
\text { institutional action plans). }\end{array}$ \\
\hline $\begin{array}{l}\text { 1-2 h EvaluationSessions } \\
\text { Adaptive Solutions }\end{array}$ & $\begin{array}{l}\text { Steering: six monthly sessions to identify subsystem changes and } \\
\text { modifications to the systems map (outcomes such as individual child } \\
\text { measures, process change; follow up system measures). }\end{array}$ \\
\hline
\end{tabular}

\subsection{Characterizing and Intervening in Systems}

Using Action Research [29] and Knowledge Translation and Exchange frameworks [30], the nature of the intervention is allowed to iterate and develop over time. The following measures will be taken and be fed back to progressive design and implementation support workshops described above.

Systems Maps

Group model building (GMB) will be used to develop causal maps (causal loop diagrams) as qualitative representations of the feedback mechanisms and delays of systems driving obesity trends within each community. GMB is a participatory systems science method for engaging stakeholders in the process of developing informal maps and formal models with computer simulation [31]. Central to GMB is the explicit design and facilitation of a sequence of boundary objects that allow all diverse stakeholders to describe dependencies between different elements of systems [32-34].

The GMB workshops comprise facilitated activities that provide the skills and techniques necessary for participants to develop system maps using GMB scripts [35,36]. In each community, an evidence-based, community-specific systems logic model will be co-developed and validated by participants and researchers and priority actions formed. Subsequent workshops (six monthly) will identify subsystems changes and modifications to systems. Quantitative data will be collected to describe key variables in the system logic model. Where data are not available, community measures of variable strength and change will be collected. These data will be used for the economic analysis to describe the level and cost of intervention activity in relation to the measured outcome.

\subsection{Evaluation}

\subsubsection{External Control Communities}

Thirteen additional Victorian communities were selected in the 2014/2015 financial year as comparison (i.e., no intervention) sites [37]. Baseline data was collected in parallel to the baseline 
for this study from 2561 of 2959 eligible students in Victorian primary schools (response rate $=87 \%$ ). The outcome measures used were identical to those in the current proposal, collected under an opt-out consent model, and in regions geographically dispersed from the GSCRV. Measures will be repeated in 2016/2017 and 2018/2019 to provide a detailed picture of changes in BMI-z (Body Mass Index $\mathrm{z}$ score) and risk factor prevalence outside the GSCRV. This will also provide for some assessment of contamination across areas. We will be able to assess regional differences though not broader efforts. For example, we will be able to assess the effect of different localized health promotion media, though not state-wide or federal coverage.

\subsubsection{Primary and Secondary Outcomes}

Primary outcome: change in childhood BMI-z and obesity prevalence. Secondary outcomes: change in children's diet and physical activity (PA) behaviours, community systems, and settings environments for food and PA. The previously published detailed methodology of the sustainable monitoring system is briefly outlined below $[17,37]$.

\subsubsection{Anthropometry and Behaviours}

Participants will be all children in grades two (7-8 y), four (9-10 y) and six (11-12 y) available on the day of data collection at their school who have not returned an opt-out consent form. All primary schools in the GSCRV will be invited to participate using the approach outlined below.

\subsection{Measures/Instruments}

All eligible children (grades two, four and six) in consenting schools will have height and weight measured by trained personnel. Children in grades four and six will be invited to complete, on an electronic tablet (i.e., iPad), survey instruments (Table 3) selected for suitability, reliability and validity for these age groups [17].

Table 3. Primary and secondary outcomes of interests and proposed instruments.

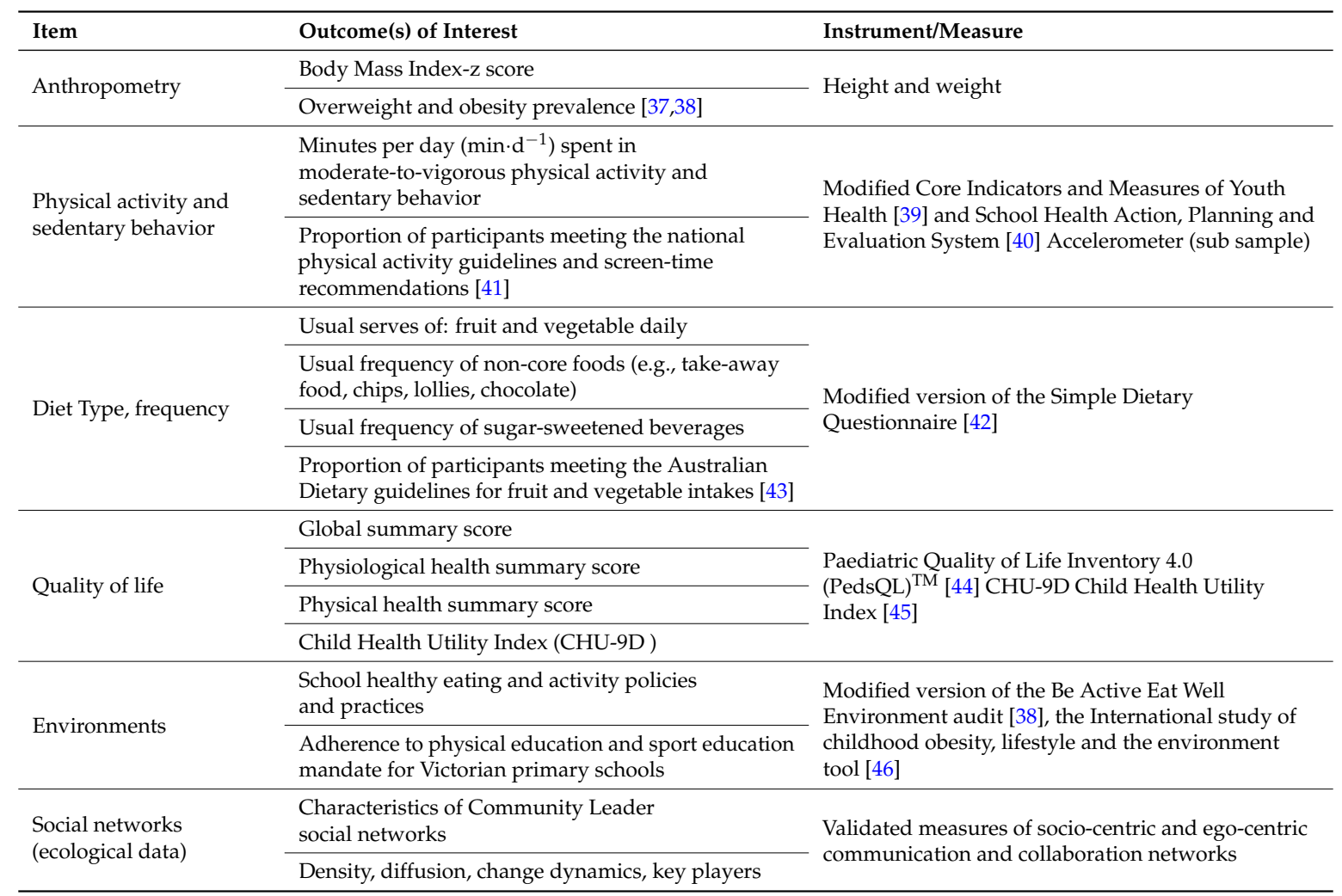




\subsection{Procedures}

In Term 1 of each study year (2015 baseline, 2017 and 2019) presentations will be made to school principal networks (agreed partners), with written invitations and an information pack sent to each school principal, followed up with phone calls and/or personal visits to recruit schools. Assembly and classroom presentations will be made to all children in the target grades regarding the study, at which time the Plain Language Statement and opt-out consent form will be distributed. All children in each target grade will be enrolled unless they return an opt-out consent form signed by their parents/guardians or opt out verbally. Measurements will typically be conducted over a one-day visit to each school in the second term of each year (March to June). A team of up to six trained data collectors (all with current Working with Children Checks or equivalent) will collect anthropometric and survey data in one class period. Data collectors will be trained by study leads in anthropometric measurement, accelerometer fitting, questionnaire delivery and sensitivity when engaging young children.

\subsection{Sample Size}

Based on school enrolment data, we estimate that there are 5050 children in the GSCRV in grades two, four or six across 84 primary schools in the region. Using an opt-out consent process, which delivers a $>90 \%$ response rate, and assuming that $75 \%$ of schools will participate, we expect to measure more than 3000 children at each study wave meaning 3000 observations at each step and 9000 across the three study data points. BMI-z standard deviation (1.2) and intra-cluster correlation (0.027) were estimated in a previous study of $>2500$ Victorian school children (2014-2015). Under the stepped wedge design (ten clusters, three data collection points, five clusters) randomized to intervention at step 1 , there will be an average of 300 children in each cluster, and the minimum detectable difference in BMI-z between groups with $80 \%$ power will be 0.13 . This compares favourably with the observed difference achieved in previous successful intervention studies in children of 0.18 , which was associated with a $3 \%$ reduction in prevalence of overweight and obesity over three years [7-9].

While the power for the current study is based on the stepped wedge design alone, the external parallel control group of 13 communities will add an additional comparative power to this trial.

\subsection{Environmental Audits}

Environmental audits will be conducted using a modified version of the Schools' Environmental Audit survey [46] including elements of the international study of childhood obesity, lifestyle and the environment (ISCOLE) survey [46].

\subsection{Ethics Approvals}

Full ethics clearances have been received for all methods described above: Deakin University's Human Research Ethics Committee (DU-HREC) 2014-279, DU-HREC 2013-095, Deakin University's Human Ethics Advisory Group-Health (HEAG-H) HEAG-H 194_2014, HEAG-H 17 2015, HEAG-H 155_2014), the Victorian Department of Education and Training 2015_002622, 2013_002013, and the Catholic Archdiocese of Melbourne, Sale, Sandhurst and Ballarat.

\section{Analysis Plan}

Social network analysis (SNA) [47] will be used to quantify the strength and importance of relationships among people and organizations who have control over environments that affect children's health [48]. Social network analysis software (e.g., "SNA" and "network" in R [49] will be used to calculate network statistics for each community including density and centrality and "opinion leader" positions, which are statistics used to identify people in the network who send or receive the most connections to others (the former indicating influence, the latter prominence), or who occupy other central or bridging positions in a network that are important to network diffusion and connecting relatively disconnected areas of the network. Social network dynamics will be modeled 
using longitudinal network models to determine how the networks change over time, the factors that predict the formation and maintenance of new relationships, and the role of the network in the diffusion information, knowledge and practice. Additional systems measurement will comprise evaluation of change in systems maps, tracking of change in subsystems and process evaluation of the communities' responses to the systems intervention. The grounded logic models developed through this process will also allow the addition of other data sources, whether bespoke or routine data, for an understanding of the change in systems.

The effect of the intervention on the main outcome (BMI-z) will be assessed using a linear mixed model with cluster as a random effect (community) and time (step), intervention and interaction of time by intervention as fixed effects. Because intervention enrolment will be staggered, data will be analyzed following two different approaches: (1) an intention to treat principle irrespective of when the enrolment effectively occurred; and (2) considering actual enrolment time. Secondary outcomes will be analyzed by fitting a generalized linear mixed model with link and distribution selected according to the variable (Figure 2). Missing outcomes (which we anticipate will be sparse due to the selection criteria "child present at school on the day of data collection") will be managed using an inverse probability weighting approach.

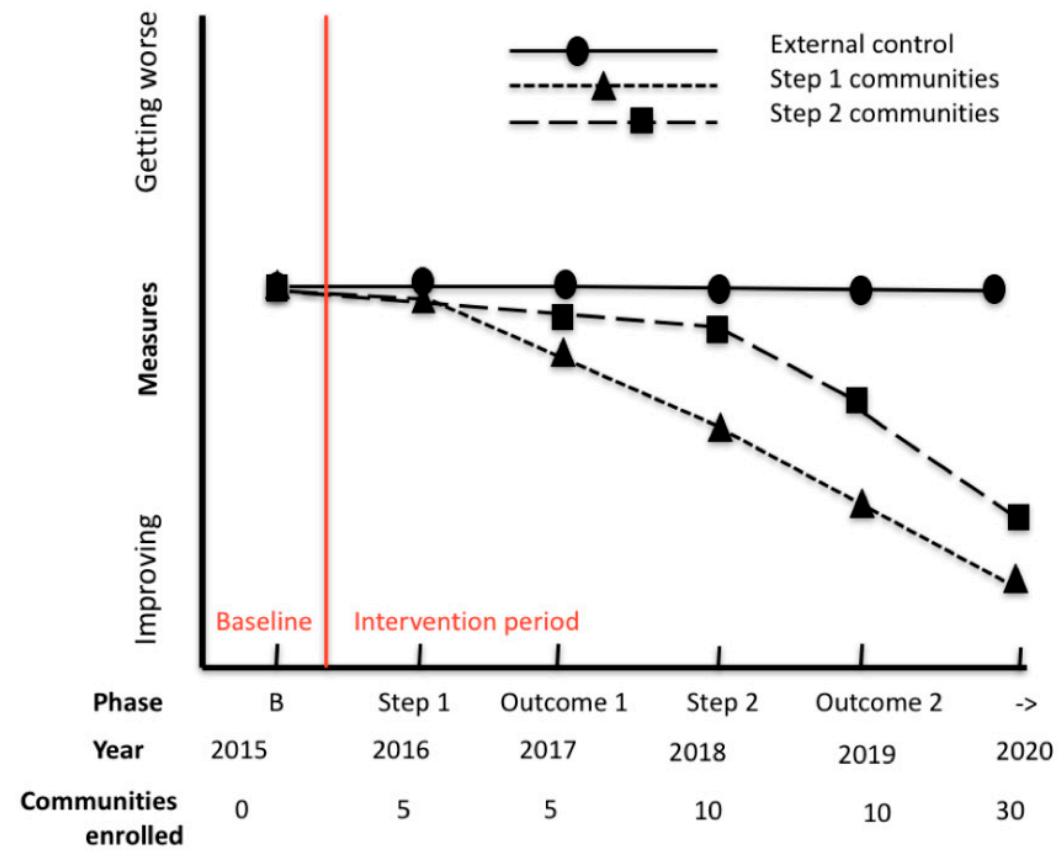

Figure 2. Hypothesis testing over time for the WHO STOPS trial.

\section{Economic Evaluation}

The economic appraisal will assess from a "societal" and "health sector perspective" whether the intervention is value-for-money compared to current practice [50,51]. A trial-based analysis will be undertaken utilizing data collected in the trial, as will economic modelling to estimate longer-term quality of life and health sector offsets using best available information. Evaluation approaches will include cost-effectiveness analysis (CEA) focusing on obesity prevalence; cost-utility analysis (CUA) using the Child Health Utility instrument (CHU-9D) to elicit changes in participant quality of life levels; and cost-consequences analysis (CCA), which will identify other benefit considerations such as equity impacts, acceptability to stakeholders, affordability/sustainability and strength of evidence, as well as analyzing the extent of community investment in obesity-related prevention action for every dollar of public investment. A pathway approach will underpin the cost analysis, with clear specification of intervention activities and associated unit prices. 
Beyond the facilitated workshops, this intervention explicitly asks each community to operationalize the intervention. This raises a number of methodological issues for the economic evaluation, such as: (i) attribution of each community's subsequent actions to the intervention; (ii) capturing data on the extent, nature and costs of these downstream actions; (iii) attribution of the costs associated with these downstream community and household actions; and (iv) assessing which action(s) have the most positive impact. Resolution of these issues is difficult to specify in advance-there is no established practice in applying economic evaluation to a systems setting. Accordingly, we will pilot test alternative methods by conducting a retrospective economic evaluation in the project's pilot community, which is one year post initial intervention exposure. Detailed methods for the full economic evaluation will be finalized after careful consideration of lessons learned from the pilot economic evaluation.

\section{Conclusions}

Current evidence points to systems science as the best way of identifying and addressing the complex and dynamic causes of obesity. WHO STOPS sets out to understand the ways in which the application of systems thinking could prevent childhood obesity.

Acknowledgments: Steven Allender is supported by funding from an Australian National Health and Medical Research Council/Australian National Heart Foundation Career Development Fellowship (APP1045836). He is also a researcher on the U.S. National Institutes of Health grant titled, "Systems Science to Guide Whole of Community Childhood Obesity Interventions" (1R01HL115485-01A1). This study is supported by a NHMRC Partnership Project titled "Whole of Systems Trial of Prevention Strategies for childhood obesity: WHO STOPS childhood obesity" (APP1114118). The work described herein has also received funding support from the Western Alliance and the Ian Potter Foundation. Steven Allender, Lynne Millar, Colin Bell, Claudia Strugnell, Marj Moodie, Rob Carter, Boyd Swinburn are researchers within the NHMRC Centre for Research Excellence in Obesity Policy and Food Systems (APP1041020).

Author Contributions: All authors contributed significant text and intellectual input into all aspects of the manuscript. All authors conceived the experiments described in this paper. Steven Allender, Lynne Millar, Claudia Strugnell and Boyd Swinburn conceived the monitoring approach described, Rob Carter and Marj Moodie conceived the economics analysis, Steven Allender Liliana Orellana and Claudia Strugnell conceived the approach to analysing outcomes data, Kayla de la Haye conceived the social network methods, Steven Allender, Peter Hovmand, Colin Bell, Janette Lowe, and Sue Morgan conceived the partnership and implementation approach described. All authors contributed to the writing of the paper.

Conflicts of Interest: The authors declare no conflict of interest.

\section{Abbreviations}

The following abbreviations are used in this manuscript:

$\begin{array}{ll}\text { ABM } & \text { Agent-Based Model } \\ \text { ACTRN } & \text { Australian New Zealand Clinical Trials } \\ \text { BAEW } & \text { Be Active Eat Well } \\ \text { BMI } & \text { Body Mass Index } \\ \text { BMI-z } & \text { Body Mass Index z score } \\ \text { DES } & \text { Discrete Event Simulation } \\ \text { DU-HREC } & \text { Deakin University's Human Research Ethics Committee } \\ \text { GLOBE } & \text { Global Obesity Centre } \\ \text { GMB } & \text { Group Model Building } \\ \text { GSCRV } & \text { Great South Coast Region of Victoria } \\ \text { HEAG-H } & \text { Deakin University's Human Ethics Advisory Group-Health } \\ \text { ISCOLE } & \text { International Study of Childhood Obesity, Lifestyle and the Environment } \\ \text { SD } & \text { System Dynamics } \\ \text { SNA } & \text { Social Network Snalysis } \\ \text { WHO } & \text { World Health Organization } \\ \text { STOPS } & \text { Whole of Systems Trial of Prevention Strategies }\end{array}$

\section{References}

1. Colagiuri, S.; Lee, C.M.Y.; Colagiuri, R.; Magliano, D.; Shaw, J.E.; Zimmet, P.Z.; Caterson, I.D. The cost of overweight and obesity in Australia. Med. J. Aust. 2010, 192, 260-264. [PubMed] 
2. Australian Bureau of Statistics. Australian Health Survey: First Results, 2014-2015. Available online: http:/ /www.abs.gov.au/ausstats/abs@.nsf/mf/4364.0.55.001 (accessed on 22 March 2016).

3. Hoad, V.; Somerford, P.; Katzenellenbogen, J. High body mass index overtakes tobacco as the leading independent risk factor contributing to disease burden in Western Australia. Aust. N. Z. J. Public Health 2010, 34, 214-215. [CrossRef] [PubMed]

4. Singh, A.; Mulder, C.; Twisk, J.; van Mechelen, W.; Chinapaw, M. Tracking of childhood overweight into adulthood: A systematic review of the literature. Obes. Rev. 2008, 9, 474-488. [CrossRef] [PubMed]

5. World Health Organization. Global Action Plan for the Prevention and Control of Noncommunicable Diseases 2013-2020; World Health Organization: Geneva, Switzerland, 2013.

6. Waters, E.; de Silva-Sanigorski, A.; Hall, B.J.; Brown, T.; Campbell, K.J.; Gao, Y.; Armstrong, R.; Prosser, L.; Summerbell, C.D. Interventions for preventing obesity in children. Cochrane Database Syst. Rev. 2011. [CrossRef]

7. De Silva-Sanigorski, A.M.; Bell, A.C.; Kremer, P.; Nichols, M.; Crellin, M.; Smith, M.; Sharp, S.; de Groot, F.; Carpenter, L.; Boak, R.; et al. Reducing obesity in early childhood: Results from Romp \& Chomp, an Australian community-wide intervention program. Am. J. Clin. Nutr. 2010, 91, 831-840. [PubMed]

8. Millar, L.; Kremer, P.; de Silva-Sanigorski, A.; McCabe, M.; Mavoa, H.; Moodie, M.; Utter, J.; Bell, C.; Malakellis, M.; Mathews, L.; et al. Reduction in overweight and obesity from a 3 year community-based intervention in Australia: The "It's Your Move!" project. Obes. Rev. 2011, 12, 20-28. [CrossRef] [PubMed]

9. Sanigorski, A.M.; Bell, A.C.; Kremer, P.J.; Cuttler, R.; Swinburn, B.A. Reducing unhealthy weight gain in children through community capacity-building: Results of a quasi-experimental intervention program, Be Active Eat Well. Int. J. Obes. 2008, 32, 1060-1067. [CrossRef] [PubMed]

10. Millar, L.; Robertson, N.; Allender, S.; Nichols, M.; Bennett, C.; Swinburn, B. Increasing community capacity and decreasing prevalence of overweight and obesity in a community based intervention among Australian adolescents. Prev. Med. 2013, 56, 379-384. [CrossRef] [PubMed]

11. Swinburn, B.; Dietz, W.; Kleinert, S. A lancet commission on obesity. Lancet 2015, 386, 1716-1717. [CrossRef]

12. Gortmaker, S.L.; Swinburn, B.A.; Levy, D.; Carter, R.; Mabry, P.L.; Finegood, D.T.; Huang, T.; Marsh, T.; Moodie, M.L. Changing the future of obesity: Science, policy, and action. Lancet 2011, 378, 838-847. [CrossRef]

13. New Zealand Government. Healthy Families New Zealand. Available online: http://www.healthyfamilies. govt.nz/\#home-2 (accessed on 3 November 2015).

14. Leeds Beckett University. Whole Systems Approach to Tackle Obesity. Available online: http://www. leedsbeckett.ac.uk/wholesystemsobesity/ (accessed on 12 August 2016).

15. Sorensen, G.; Emmons, K.; Hunt, M.K.; Johnston, D. Implications of the results of community intervention trials. Ann. Rev. Public Health 1998, 19, 379-416. [CrossRef] [PubMed]

16. Richardson, G.P. Reflections on the foundations of system dynamics. Sys. Dyn. Rev. 2011, 27, $219-243$. [CrossRef]

17. Crooks, N.; Strugnell, C.; Bell, C.; Allender, S. A sustainable and high participation childhood obesity monitoring system in regional Victoria, Australia. Aust. N. Z. J. Public Health 2016. Accepted.

18. Brown, C.A.; Lilford, R.J. The stepped wedge trial design: A systematic review. BMC Med. Res. Methodol. 2006, 6, 54-54. [CrossRef] [PubMed]

19. Hainaut, P. The Gambia hepatitis intervention study (GHIS). Iatreia 2007, 20, S21-S22.

20. Brimblecombe, J.; Ferguson, M.; Liberato, S.C.; Ball, K.; Moodie, M.L.; Magnus, A.; Miles, E.; Leach, A.J.; Chatfield, M.D.; Mhurchu, C.N.; et al. Stores healthy options project in remote indigenous communities (SHOP@RIC): A protocol of a randomised trial promoting healthy food and beverage purchases through price discounts and in-store nutrition education. BMC Public Health 2013, 13. [CrossRef] [PubMed]

21. Hemming, K.; Lilford, R.; Girling, A.J. Stepped-wedge cluster randomised controlled trials: A generic framework including parallel and multiple-level designs. Stat. Med. 2015, 34, 181-196. [CrossRef] [PubMed]

22. Hawkins, N.G.; Sanson-Fisher, R.W.; Shakeshaft, A.; D’Este, C.; Green, L.W. Theme article: The multiple baseline design for evaluating population-based research. Am. J. Prev. Med. 2007, 33, 162-168. [CrossRef] [PubMed]

23. Mdege, N.D.; Man, M.S.; Taylor Nee Brown, C.A.; Torgerson, D.J. Systematic review of stepped wedge cluster randomized trials shows that design is particularly used to evaluate interventions during routine implementation. J. Clin. Epidemiol. 2011, 64, 936-948. [CrossRef] [PubMed] 
24. World Health Organization. Everybody Business: Strengthening Health Systems to Improve Health Outcomes: Who's Framework for Action. Available online: http://www.wpro.who.int/health_services/health_systems_ framework/en/ (accessed on 21 July 2016).

25. World Health Organization. Monitoring the Building Blocks of Health Systems: A Handbook of Indicators and Their Measurement Strategies. Available online: http://www.who.int/healthinfo/systems/WHO_MBHSS_ 2010_full_web.pdf (accessed on 28 August 2016).

26. Department of Health New South Wales. A Framework for Building Capacity to Improve Health; Department of Health Sydney: Sydney, Australia, 2001.

27. Allender, S.; Owen, B.; Whelan, J.; Kuhlberg, J.; Lowe, J.; Nagorcka-Smith, P.; Bell, C. A community based systems diagram of obesity causes. PLoS ONE 2015, 10. [CrossRef] [PubMed]

28. Simmons, A.; Reynolds, R.C.; Swinburn, B. Review: Defining community capacity building: Is it possible? Prev. Med. 2011, 52, 193-199. [PubMed]

29. Carr, W.; Kemmis, S. Becoming Critical: Education, Knowledge and Action Research; Deakin University Press: Burwood, Australia, 1986.

30. Graham, I.D.; Logan, J.; Harrison, M.B.; Straus, S.E.; Tetroe, J.; Caswell, W.; Robinson, N. Lost in knowledge translation: Time for a map? J. Contin. Educ. Health Prof. 2006, 26, 13-24. [CrossRef] [PubMed]

31. Rose, J.; Riolo, R.; Hovmand, P.S.; Cherng, S.; Ferrer, R.; Katerndahl, D.A. Modeling the paradox of primary care. In Handbook of Systems and Complexity in Health; Sturmberg, J.P., Martin, C.M., Eds.; Springer: Chicago, IL, USA, 2013.

32. Black, L.J. When visual representations are boundary objects in system dynamics work. Syst. Dynam. Rev. 2013, 29, 70-86. [CrossRef]

33. Black, L.J.; Andersen, D.F. Using visual representations as boundary objects to resolve conflict in collaborative model-building applications. Syst. Res. Behav. Sci. 2012, 29, 194-208. [CrossRef]

34. Hovmand, P.S. Community Based System Dynamics; Springer: New York, NY, USA, 2014.

35. Hovmand, P.S.; Andersen, D.F.; Rouwette, E.; Richardson, G.P.; Rux, K.; Calhoun, A. Group model building "scripts" as a collaborative tool. Syst. Res. Behav. Sci. 2012, 29, 179-193. [CrossRef]

36. Scriptapedia. Available online: https://en.wikibooks.org/wiki/Scriptapedia (accessed on 15 June 2016).

37. Strugnell, C.; Millar, L.; Churchill, A.; Jacka, F.; Bell, C.; Malakellis, M.; Swinburn, B.; Allender, S. Healthy together Victoria and childhood obesity-a methodology for measuring changes in childhood obesity in response to a community-based, whole of system cluster randomized control trial. Arch. Public Health 2016, 74. [CrossRef] [PubMed]

38. Mathews, L.; Kremer, P.; Sanigorski, A.; Simmons, A.; Nichols, M.; Moodie, M. Nutrition and Physical Activity in Children and Adolescents; Report 1: Methods and Tools; Department of Human Services (Victoria): Victoria, Australia, 2009.

39. Card, A.; Manske, S.; Mammen, G.; King, M.; Gleddie, D.; Schwartz Mobo, Y.E. Core Indicators and Measures of Youth Health Physical Activity and Sedentary Behaviour Module: Indicators and Questions to Use with Youth Respondents and/or School Setting Assessments; Memorial University of Newfoundland: St. John's, NL, Canada, 2012.

40. Wong, S.L.; Leatherdale, S.T.; Manske, S.R. ReliFability and validity of a school-based physical activity questionnaire. Med. Sci. Sports Exerc. 2006, 38, 1593-1600. [CrossRef] [PubMed]

41. Department of Health. Australia's Physical Activity and Sedentary Behaviour Guidelines Canberra: Australian Government. Available online: http://www.health.gov.au/internet/main/publishing.nsf/ content/health-pubhlth-strateg-phys-act-guidelines\#apa512 (accessed on 25 August 2014).

42. Parletta, N.; Cooper, P.; Petkov, J.; O'Dea, K. Effects of fish oil supplementation on learning and behaviour of children from Australian Indigenous remote community schools: A randomised control trial. Prostagland Leuk. Essent. Fatty Acid. 2013, 89. [CrossRef] [PubMed]

43. National Health and Medical Research Council. Eat for Health: Australian Dietary Guidelines Summary Canberra: Australian Government. Available online: https://www.eatforhealth.gov.au/sites/default/Ffiles/ files/the_guidelines/n55a_australian_dietary_guidelines_summary_book.pdf (accessed on 4 April 2013).

44. Varni, J.W.; Limbers, C.A.; Burwinkle, T.M. How young can children reliably and validly self-report their health-related quality of life? An analysis of 8591 children across age subgroups with the PedsQL 4.0 Generic Core Scales. Health Qual. Life Outcomes 2007, 5. [CrossRef] 
45. Stevens, K.J. Working with children to develop dimensions for a preference-based, generic, pediatric, health-related quality-of-life measure. Qual. Health Res. 2010, 20, 340-351. [CrossRef] [PubMed]

46. Katzmarzyk, P.T.; Barreira, T.V.; Broyles, S.T.; Champagne, C.M.; Chaput, J.-P.; Fogelholm, M.; Hu, G.; Johnson, W.D.; Kuriyan, R.; Kurpad, A.; et al. The international study of childhood obesity, lifestyle and the environment (ISCOLE): Design and methods. BMC Public Health 2013, 13, 1-13. [CrossRef] [PubMed]

47. Scholz, J.T.; Kile, B.; Berardo, R. Do networks solve collective action problems? Credibility, search, and collaboration. J. Polit. 2008, 70, 393-406. [CrossRef]

48. Carrington, P.J.; Scott, J.; Wasserman, S. Models and Methods in Social Network Analysis; Cambridge University Press: Cambridge, UK, 2005.

49. R Core Team. R: A Language and Environment for Statistical Computing; R Foundation for Statistical Computing: Vienna, Austria.

50. Carter, R.; Moodie, M.; Markwick, A.; Magnus, A.; Vos, T.; Swinburn, B.; Haby, M.M. Assessing cost-effectiveness in obesity (ACE-Obesity): An overview of the ACE approach, economic methods and cost results. BMC Public Health 2009, 9. [CrossRef] [PubMed]

51. Vos, T.; Carter, R.; Barendregt, J.; Mihalopoulos, C.; Veerman, L.; Magnus, A. Assessing Cost-Effectiveness in Prevention: (ACE-Prevention): Final Report; Centre for Burden of Disease and Cost Effectiveness, School of Population Health, University of Queensland: Brisbane, Australia, 2010.

(C) 2016 by the authors; licensee MDPI, Basel, Switzerland. This article is an open access article distributed under the terms and conditions of the Creative Commons Attribution (CC-BY) license (http://creativecommons.org/licenses/by/4.0/). 


\section{University Library}

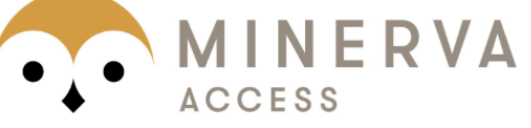

A gateway to Melbourne's research publications

Minerva Access is the Institutional Repository of The University of Melbourne

\section{Author/s:}

Allender, S;Millar, L;Hovmand, P;Bell, C;Moodie, M;Carter, R;Swinburn, B;Strugnell, C;Lowe, J;de la Haye, K;Orellana, L;Morgan, S

Title:

Whole of Systems Trial of Prevention Strategies for Childhood Obesity: WHO STOPS Childhood Obesity

Date:

2016-11-01

Citation:

Allender, S., Millar, L., Hovmand, P., Bell, C., Moodie, M., Carter, R., Swinburn, B., Strugnell, C., Lowe, J., de la Haye, K., Orellana, L. \& Morgan, S. (2016). Whole of Systems Trial of Prevention Strategies for Childhood Obesity: WHO STOPS Childhood Obesity. INTERNATIONAL JOURNAL OF ENVIRONMENTAL RESEARCH AND PUBLIC HEALTH, 13 (11), https://doi.org/10.3390/ijerph13111143.

Persistent Link:

http://hdl.handle.net/11343/254701

License:

CC BY 